\title{
ON THE BACKWARD PROBLEMS IN TIME FOR TIME-FRACTIONAL SUBDIFFUSION EQUATIONS
}

\author{
SHAVKAT Alimov AND RAVSHAN ASHUROV*
}

\begin{abstract}
The backward problem for subdiffusion equation with the fractional Riemann-Liouville time-derivative of order $\rho \in(0,1)$ and an arbitrary positive self-adjoint operator $A$ is considered. This problem is ill-posed in the sense of Hadamard due to the lack of stability of the solution. Nevertheless, we will show that if we consider sufficiently smooth current information, then the solution exists and it is unique. Using this result, we study the inverse problem of initial value identification for subdiffusion equation. The results obtained differ significantly from the corresponding results for the classical diffusion equation (i.e. $\rho=1$ ) and even for the subdiffusion equation with the Caputo derivative. A list of examples of operator $A$ is discussed, including linear systems of fractional differential equations, differential models with involution, fractional Sturm-Liouville operators, and many others.
\end{abstract}

Mathematics subject classification (2020): Primary 35R11; Secondary 34A12.

Keywords and phrases: Backward problem, Riemann-Liouville derivatives, subdiffusion equation.

\section{REFERENCES}

[1] A. Kochubei, Yu. Luchko, Handbook of Fractional Calculus with Applications, Vol. 2, De Gruyter (2019).

[2] A. A. Kilbas, H. M. SRivastava, J. J. Trujillo, Theory and applications of fractional differential equations, ELSEVIER (2006).

[3] B. Ahmad, A. Alsaedi, M. Kirane, Blowing-up solutions of distributed fractional differential systems, Chaos, Solitons and Fractals, 145, No. 1 (2021), 1-4.

[4] A. Als aedi, B. Ahmad, M. Kirane, B. T. TorebeK, Blowing-up solutions of the time-fractional dispersive equations, Adv. Nonlinear Anal. 10 (2021), 952-971.

[5] S. Umarov, M. Hahn, K. Kobayashi, Beyond the triangle: Browian motion, Ito calculas, and Fokker-Plank equation-fractional generalizations, World Scientific (2017).

[6] Z. Li, Y. LiU, M. Yамамото, Inverse problems of determining parameters of the fractional partial differential equations, Handbook of fractional calculus with applications, Vol. 2, De Gruyter (2019), 431-442.

[7] R. R. Ashurov, S. Umarov, Determination of the order of fractional derivative for subdiffusion equations, Fractional Calculus and Applied Analusis, 23, No. 6 (2020), 1647-1662.

[8] Sh. A. Alimov, R. R. Ashurov, Inverse problem of determining an order of the Caputo timefractional derivative for a subdiffusion equation, J. Inverse Ill-Posed Probl., 28, No. 5 (2020), 651658.

[9] R. R. Ashurov, O. Muhiddinova, Inverse problem of determining the heat source density for the subdiffusion equation, Differential Equations, 56, No. 12 (2020), 1550-1563.

[10] R. R. Ashurov, R. T. Zunnunov, Initial-boundary value and inverse problems for subdiffusion equation in $R^{N}$, Fractional differential calculus, 10, No. 2 (2020), 291-306.

[11] K. M. Furati, O. S. IYIOLA, M. KiRANE, An inverse problem for a generalized fractional diffusion, Applied Mathematics and Computation, 249 (2014), 24-31.

[12] M. Ruzhansky, N. Tokmagambetov, B. Torebek, Inverse source problems for positive operators. I: Hypoelliptic diffusion and subdiffusion equations, J. Inverse Ill-Possed Probl. 27 (2019), 891-911. 
[13] M. Kirane, B. Samet, B. T. Torebek, Determination of an unknown source term and the temperature distribution for the subdiffusion equation at the initial and final data, Journal of Differential Equations, 217 (2017), 1-13.

[14] J. J. LiU AND M. YAMAмоTO, A backward problem for the time-fractional diffusion equation, Appl. Anal., 89 (2010), 1769-1788.

[15] K. S АKАмото AND M. YАMАмото, Initial value/boundary value problems for fractional diffusionwave equations and applications to some inverse problems, J. Math. Anal. Appl., 382 (2011), 426-447.

[16] G. Florida, Z. Li, M. YAmAMOTO, Well-posedness for the backward problems in time for general time-fractional difussion equation, Rend. Lincei Mat. Appl., 31 (2020), 593-610.

[17] N. H. TUAN, L.N. HuYNH, T. B. NGOC, AND Y. ZHOU, On a backward problem for nonlinear fractional diffusion equations, Applied Mathematics Letters, 92 (2019), 76-84.

[18] C. Lizama, Abstract linear fractional evolution equations, Handbook of fractional calculus with applications, Vol. 2 (2019).

[19] N. H. TUAN, L. D. LONG, AND S. TATAR, Tikhonov regularization method for a backward problem for the inhomogeneous time-fractional diffusion equation, Appl. Anal., 97 (2018), 842-863.

[20] L. WANG AND J. J. LIU, Total variation regularization for a backward timefractional diffusion problem, Inverse Problems, 29 (2013), 115-131.

[21] R. R. Ashurov, A. CABADA, B. Turmetov, Operator method for construction of solutions of linear fractional differential equations with constant coefficients, Fractional Calculus and Applied Analusis, 1 (2016), 229-252.

[22] R. Ashurov, Yu. FAYZIEv, On construction of solutions of linear fractional differentional equations with constant coefficients and the fractional derivatives, Uzb. Math. Journ. 3 (2017), 3-21, (in Russian).

[23] S. I. KABANIKHIN, Inverse and Ill-Posed Problems. Theory and Applications, De Gruyter (2011).

[24] A. V. PSKHU, Fractional partial differential equations, (in Russian), M. NAUKA (2005).

[25] R. Gorenflo, Yu. LuchKo, M. YAmamoto, Time-fractional diffusion equation in the fractional Sobolev spaces, Fractional Calculus and Applied Analusis, 18 (2015), 799-820.

[26] A. KUBICA, M. YАмАмото, Initial-boundary value problems for fractional diffusion equations with time-dependent coefficients, Fractional Calculus and Applied Analusis, 21 (2018), 276-311.

[27] O. P. Agrawal, Solution for a fractional diffusion-wave equation defined in a bounded domain, Nonlin. Dynam. 29 (2002), 145-155.

[28] YU. LuCHKO, Some uniqueness and existence results for the initial-boundary value problems for the generalized time-fractional diffusion equation, Comput. Math. Appl., 59 (2010) 1766-1772.

[29] A. V. PSKHU, Initial-value problem for a linear ordinary differential equation of noninteger order, Sbornik: Mathematics 202 (2011), 571-582.

[30] S. R. UMARov, Introduction to Fractional and Pseudo-Differential Equations with Singular Symbols, Springer (2015).

[31] R. R. Ashurov, O. Muhiddinova, Initial-boundary value problem for a time-fractional subdiffusion equation with an arbitrary elliptic differential operator, Lobachevski Journal of Mathematics, $\mathbf{4 2}$, No. 3 (2021), 517-525.

[32] M. M. DZherbashian [=DJRbashian], Integral Transforms and Representation of Functions in the Complex Domain, (in Russian), M. NAUKA (1966).

[33] R. Gorenflo, A. A. Kilbas, F. Mainardi, S. V. Rogozin, Mittag-Leffler functions, related topics and applications, Springer (2014).

[34] V. A. IL'IN, A. F. FILIPPOV, The character of the spectrum of a selfadjoint extension of the Laplace operator in a bounded region (fundamental systems of functions with an arbitrary preassigned subsequence of fundamental numbers), Dokl. Akad. Nauk SSSR, 191, No. 2 (1970), 267-269.

[35] N. Dunford and J. T. Schwartz, Linear Operators, Part II, Spectral Theory, Interscience Publishers, NY-London (1963). 